\title{
Development
}

\section{A reflection on ten years experience of providing qualitative research training in primary care}

\begin{abstract}
Valerie A. Featherstone The Wolds Primary Care Research Network (WoReN)*, EastYorkshire, UK, Rosaline S. Barbour School of Nursing and Midwifery, University of Dundee, and Facilitator for the Workshops and Julie Garner The Wolds Primary Care Research Network (WoReN), EastYorkshire, UK
\end{abstract}

\begin{abstract}
Aims: To gain structured feedback on a qualitative research methods training programme delivered to primary care researchers over a period of ten years. To examine dilemmas and challenges and how these had been resolved. To examine how the programme could be further developed. Background: The Wolds Primary Care Research Network's (WoReN) qualitative research methods training programme was developed and evolved in response to the needs of primary care practitioners and researchers and the NHS Research Agenda. Methods: Information on participants' professional backgrounds: which workshops they attended; their evaluation sheets, comments; and personal appraisals were collected from 1996 to 2006. Structured telephone conversations with a number of participants and ongoing informal feedback from participants added to this information. Numbers and ranges of professionals attending workshops were ascertained, how far they travelled to workshops and further degrees obtained by them, within the decade, were also noted. Findings: We found a lack of similar training elsewhere. A wide range of people attended workshops, especially general practitioners (GP) and academic researchers. Other practitioners were a significant presence however, and included nurses, pharmacists, health visitors and professions allied to medicine. Participants were prepared to attend extended workshops and to travel significant distances to them. Participants preferred a continuous cycle of workshops rather than discreet sessions, in order for them to consolidate their learning and to develop at their own pace. Practical exercises reflecting the qualitative research process were considered very conducive to learning and participants also appreciated one-to-one consultations about their work and longer-term, ongoing support as they progressed through their projects. Workshop design needed to continually reflect the changing requirements of participants, employers, funders, potential trainers and national NHS requirements. A new audience for training was identified in supervisors not versed in the qualitative paradigm.
\end{abstract}

Key words: primary health care; qualitative research; teaching methods; training of trainers

Received: December 2005; accepted: November 2006

\footnotetext{
Address for correspondence: Valerie A. Featherstone, WoReN, Trust Headquarters, Willerby Hill, Beverley Road, Willerby, HU10 6ED, UK. Email: Val.featherstone@hullpct.nhs.uk

* This is funded by The National Co-ordinating Centre for Research Capacity Development.

(C) 2007 Cambridge University Press
} 
The Wolds Primary Care Research Network's $(\mathrm{WoReN})^{1}$ qualitative research methods training programme was developed in response to the growing acceptance of, and enthusiasm for, the paradigm and the commensurate increase in demand for training by primary care researchers. Primary care research networks were conduits through which some of the large, national NHS research and development agenda at that time was to be delivered. This emphasized the importance of filling in gaps in the evidence base in primary care by primary care practitioners themselves, in order to inform clinical practice (Mant et al., 2004).

We describe here how the programme evolved; how useful it has been to primary care researchers; the dilemmas and challenges encountered in design and delivery; and how we attempted to resolve these. We reflect on how the programme could be further developed in the light of our experience and participants' increasing expertise and changing requirements.

Information on participants' professional backgrounds: which workshops they attended; their evaluation sheets, comments; and personal appraisals have all been collected over the last decade. Telephone conversations with a number of participants and ongoing informal feedback from participants augmented this information.

\section{The history of responsive workshop provision}

The first two-part workshop in 1997 was organized in response to a need for interview training. An initial difficulty we encountered was the relative lack of knowledge and experience of participants. Thus, we were faced with the dual challenge of rendering accessible something that was essentially quite complex in relatively short sessions, whilst hoping that we did not deter potential qualitative researchers. Some participants were simply curious about qualitative research, while others wished to embark upon projects of their own and required further training.

This original workshop evolved into three parts with the addition - at the request of participants - of a collaborative writing workshop which resulted in

\footnotetext{
${ }^{1}$ WoReN, one of many UK primary care research networks, was set up in 1996, to increase research capacity within six PCTs in East Yorkshire, North and North East Lincolnshire.
}

two published papers (Barbour et al., 2000; Barbour, Featherstone and Members of WoReN, 2000). Research career paths, time constraints and the diversity of professional backgrounds all had implications for how participants approached, experienced and handled workshops. A theme emerging during early workshops, and which constantly recurred, was participants' need for a supportive peer environment in which to discuss issues involved in 'hands-on' qualitative research.

By 1999, a lack of appropriate training provision in the use of focus groups was identified and the workshops set up in response to this need have continued to be amongst our most popular sessions,

I had never done focus groups before and needed it for a current project. It was the best thing I have ever done from a learning point of view. I would recommend it to others.

(Interview workshop participant, 1999)

This particular participant, along with a colleague, used the training to run a focus group project immediately after the workshop.

Academic researchers (including PhD students and research fellows), from a variety of disciplinary backgrounds and GPs have been the most consistent workshop attendees and attended more advanced workshops. Primary Care Trust and Health Authority staff (including those engaged in audit and management), Professions Allied to Medicine, Nurses, Pharmacists and Health Visitors have also been a significant presence (see Figure 1).

\section{Practicalities}

\section{Funding}

We were very fortunate that some funding we gained from Northern \& Yorkshire through the Regional Research Capacity Committee in 2000, afforded us the opportunity to pursue our particular approach to training. In addition to this and network funding already spent on workshops, further grants are needed to continue the existing programme. Interview workshops, in particular, are costly, requiring a main facilitator, a second facilitator who is familiar with qualitative research concepts, small break-out rooms, comprehensive workshop packs, and administrative support. Whilst maintaining small numbers - key to the

Primary Health Care Research \& Development 2007; 8: 198-206 


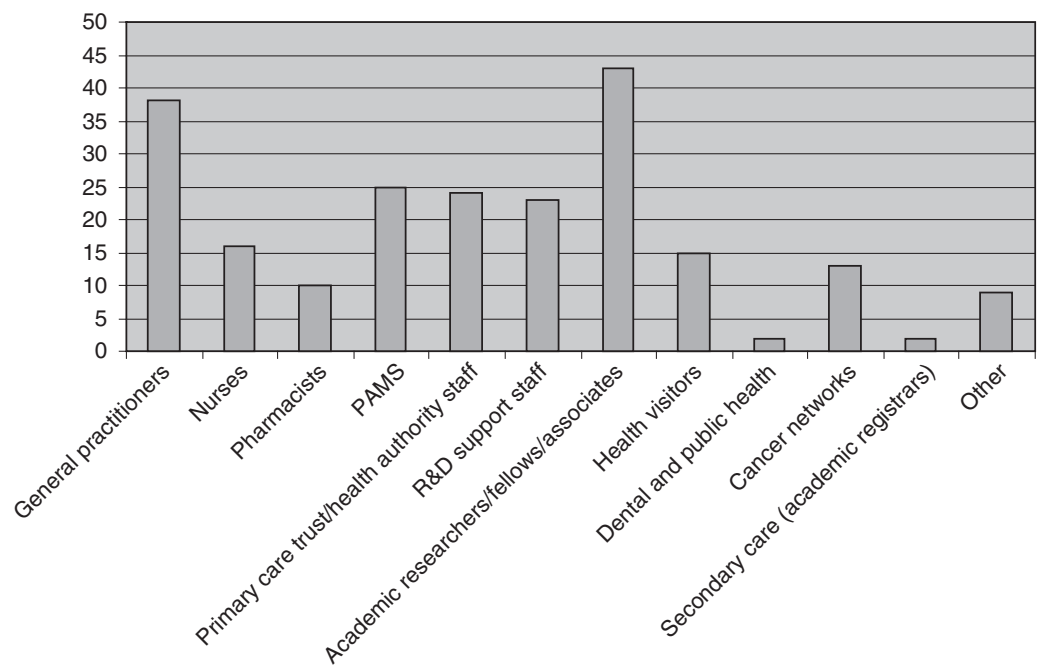

Figure 1 Number and range of professions attending workshops

impact and comfort of the workshops - it is possible to still break even financially, charging a maximum of $£ 100$ per day, per participant. ${ }^{2}$ This is still considerably less expensive for managers than sending staff to workshops outside the region would be assuming that such provision is available.

\section{Location}

In terms of the location of workshops, sessions within a 40-mile radius of Hull, in places with good transport links, were provided when the facilitator's other commitments in the region permitted. Some participants, however, travelled considerable distances to attend workshops (see Table 1).

\section{Marketing and timing of workshops}

It is difficult to predict the best time to run workshops. Whilst notifications may reach researchers at a moment coinciding appropriately with their progress, we have run workshops for researchers on demand and rescheduled workshops in response to people's availability. Advance notice of forthcoming workshops is best disseminated regionally and nationally.

\footnotetext{
${ }^{2}$ Full details of costings are available from the first author.

Primary Health Care Research \& Development 2007; 8: 198-206
}

\section{Main Challenges}

\section{Mirroring the qualitative research process}

Barbour (2001) has argued that journal requirements can drive not only how research is written up but also, perhaps more invidiously, how it is conducted. The workshop culture can serve to reinforce such unrealistic demands and the difficulty for many participants of taking time out of work to acquire training mitigates against a programme that seeks to provide thorough training through a series of linked sessions. Ideally, we wished to convey the importance of good research design and the constant cycle of revision in the process, whilst breaking down the qualitative research process into a series of manageable 'chunks'.

\section{Developing workshop materials}

A range of materials have been developed for the workshops in order to provide 'hands-on' experience of the practicalities involved in analysis and to illustrate this process. These include pre-coded excerpts from transcripts, stimulus material for focus groups, annotated transcripts, prepared summaries of theoretical papers published in peer-reviewed journals and power point presentations. Participants thus had the opportunity to begin to identify patterns in data and to engage in building up explanations for these. In addition, the workshops themselves have yielded a cumulative dataset for future use. 
Table 1 Date, location, duration, title and contents of workshops. Number of participants attending and where travelling from

Date and location Duration, title and contents

September 1997

East Yorkshire

October 1997

EastYorkshire

November 1997

East Yorkshire

September 1999

EastYorkshire

October 1999

East Yorkshire

6 March 2000

North Lincolnshire

7 May 2000

East Yorkshire

8 March 2001

East Yorkshire

February 2002

York

September 2002

York

One day workshop - Writing up qualitative research Challenges in writing up. Interrogating pre-coded data excerpts to identify patterns. Issues of presentation and representation. Individual and group writing exercises

One day workshop - NVivo computer-assisted qualitative data analysis Comprising, formulating interview schedules, one to one interview partnerships (services for drug users)

One day writing up workshop - Preparing a paper

for publication

Two day workshops - Planning and Running a

Focus Group

Eliciting and recording the data

Coding and analysing data generated

Considering writing up

Half day workshop - Computer assisted data analysis.

Nudist experience of methods and data collection

Two day focus group workshops - One week apart

How to conduct and moderate focus groups. Participation in focus groups

Analysing data using training video and working on transcribed discussions from workshop one

Two day focus group workshops - Five days apart Introduction to focus groups. Practical skills training, recording, note taking, transcribing, conducting in parallel focus groups

Introduction to analysing focus group data, general principles, field notes, partial transcripts, computer analytic induction, framework analysis, theoretical saturation and the constant comparative method

One day workshop - How to recognise, and undertake, good quality qualitative research. A revisit of issues surrounding theory, practice and writing up
No. of participants attending/travelling from

27 East Yorkshire

1 North Yorkshire

2 North Lincolnshire

12 East Yorkshire

1 North East Lincolnshire

Using transcripts from workshop one. Developing coding categories, retrieval, organization and aggregating data.

Two one hour conference workshops - An introduction to generating and analysing qualitative data. Hands-on developing topic schedules, using stimulus materials, discussions and anticipating analysis. Generating data analysis. Exploring the potential of grounded theory,

12 East Yorkshire

1 West Yorkshire

2 North Lincolnshire

1 Cleveland

1 Durham

3 East Yorkshire

1 West Yorkshire

2 North Tyneside

2 Oxfordshire

2 Staffordshire

1 London

1 Greater Manchester

9 East Yorkshire

1 West Yorkshire

1 Northamptonshire 
Table 1 (Continued)

\begin{tabular}{|c|c|c|}
\hline Date and location & Duration, title and contents & $\begin{array}{l}\text { No. of participants } \\
\text { attending/travelling from }\end{array}$ \\
\hline $\begin{array}{l}\text { May } 2004 \\
\text { East Yorkshire }\end{array}$ & One Day workshop - Action research & $\begin{array}{l}7 \text { East Yorkshire } \\
2 \text { North Yorkshire } \\
1 \text { North Lincolnshire }\end{array}$ \\
\hline $\begin{array}{l}\text { June } 2004 \\
\text { York }\end{array}$ & $\begin{array}{l}\text { Two day Master Classes and consultation slots - } \\
\text { The iterative process of qualitative data analysis } \\
\text { Developing a coding frame, coding of transcripts } \\
\text { Formulating an explanation and writing up }\end{array}$ & $\begin{array}{l}3 \text { East Yorkshire } \\
1 \text { South Yorkshire } \\
3 \text { West Yorkshire } \\
1 \text { Tyne and Wear }\end{array}$ \\
\hline $\begin{array}{l}\text { November } 2004 \\
\text { York }\end{array}$ & $\begin{array}{l}\text { Two days of Master Classes - Cultivating the craft of } \\
\text { qualitative research } \\
\text { Research design choices, generating data in focus } \\
\text { groups or one to one interview situations. Introduction } \\
\text { to analysis and coding } \\
\text { Advanced analysis, identifying patterns, interrogating } \\
\text { data. Theorizing and writing up qualitative research }\end{array}$ & $\begin{array}{l}5 \text { East Yorkshire } \\
3 \text { North Yorkshire } \\
2 \text { South Yorkshire } \\
3 \text { North Lincolnshire } \\
1 \text { Durham } \\
1 \text { Tyne and Wear } \\
1 \text { Greater Manchester }\end{array}$ \\
\hline March 2006 & $\begin{array}{l}\text { Three days of Master Classes with linked consultation } \\
\text { slots - The qualitative research process, from study } \\
\text { design to writing up } \\
\text { Introduction to qualitative research: critical appraisal } \\
\text { of qualitative papers } \\
\text { Design matters: planning qualitative research } \\
\text { Generating and analyzing qualitative data } \\
\text { Advanced data analysis and writing up: moving from } \\
\text { the descriptive to the analytical }\end{array}$ & $\begin{array}{l}12 \text { East Yorkshire } \\
1 \text { North Yorkshire } \\
2 \text { South Yorkshire } \\
1 \text { West Yorkshire } \\
2 \text { Tyne and Wear } \\
2 \text { West Midlands } \\
2 \text { South Tyneside } \\
1 \text { Devon } \\
1 \text { Leicestershire } \\
1 \text { Nottinghamshire } \\
1 \text { Lincolnshire } \\
1 \text { Derbyshire }\end{array}$ \\
\hline
\end{tabular}

\section{Meeting participants' needs}

Although it would be ideal to tailor workshops for particular levels of expertise, knowledge and experience, constraints work against ensuring that everyone's needs are met at once. We do, however, attempt to identify and respond creatively to the varying requirements and backgrounds of participants, some of whom may not have engaged in academic study for some considerable time.

The WoReN programme comprises linked, but distinctive workshops - for example, on Critical Appraisal for those who do not want to be research active themselves, but who need to be able to evaluate research papers, and on Action Research. ${ }^{3}$ Others wanting to 'dip their toes in the water' have been provided with 'taster' workshops giving a flavour of what is involved in generating and analyzing qualitative research. For those already

\footnotetext{
${ }^{3}$ Facilitated by Dr Markus Themessl-Huber, Scottish School of Primary Care, University of Dundee.
}

engaged in project work we have provided more advanced analysis workshops, including sessions on using theory in analysis and writing-up qualitative research. The recent addition of individual consultation slots following Master Classes has been very useful for researchers and the workshop facilitator offers ongoing support to participants via the network (see Table 1 for a comprehensive list of the workshops provided to date).

\section{Participants' experiences and concerns}

\section{Experiential learning}

The main and enduring hallmark of the workshop programme is the opportunity for participants to engage in 'hands-on' exercises including generating, coding and analyzing data in a supportive environment. This appears to have been one of the most significant elements throughout the workshop programme, in terms of allowing participants to 
acquire and consolidate some understanding of the qualitative research process. That is, the importance of being systematic, attending to practical constraints such as the best recording equipment to buy and being aware of the dynamics/implications of being an interviewee/interviewer or focus group moderator/participant.

Learning by doing is actually easier than having a lecture, the interaction worked well.

(Interview and writing workshop attendee, 1997)

The practical tools are useful in how to do it, the exercises are worked through and the techniques stay with you.

(Focus Group workshop attendee, 2001)

The practical exercise of focus groups and analysis are very good for learning.

(Master Class attendee, 2006)

Although we have also provided computerassisted qualitative data analysis workshops, ${ }^{4}$ the workshops have given participants the benefit of engaging first hand with the practicalities required in analyzing qualitative data, introducing them to the all-important conceptual journey involved (Barbour, 2003).

Using workshops to replicate 'real-life' research projects, we have also given participants the salutary experience of seeing their own discussions translated into text in the form of transcripts (Poland and Pedersen, 1998), which one workshop participant saw as particularly motivating. This has powerfully illustrated for them the issues and dilemmas involved although participants have been initially alarmed at the sheer volume of transcript material generated and implications for analysis.

If you're are not used to looking at transcripts, it is useful to look. It is often not how you remember it, the idea of coding is useful, conversation is so much more than the words.

(Interview workshop attendee, 1997)

Discussion has also moved along from the more technical aspects of coding onto a more analytical or theoretical level, through working with and

\footnotetext{
${ }^{4}$ Facilitated by Ann Lacey, Research Fellow, Scharr and Ann Lewins, Computer-assisted qualitative data analysis project.
}

interrogating pre-existing datasets and pre-coded data fragments,

It was really useful having plentiful examples from a 'real project', this aids memory recall.

(Master Class attendee, 2006)

The variety of personal and professional backgrounds of participants has facilitated a lively exchange of interdisciplinary ideas and debates. Interpreting data via group exercises has afforded participants the opportunity to hear the contrasting/ contradictory perceptions of different people of the same interview or focus group excerpts. These exercises have highlighted the analytic potential of reflexivity, whereby coders and analysts working together need to take account of each other's differing taken-for-granted assumptions and values (Barry et al., 1999). Participants see, when making sense of their data and formulating explanations and recommendations, how they can draw on the disciplinary knowledge of other colleagues whilst bringing their own disciplinary background, training and personal biography to bear.

\section{Further feedback and reflections on the future programme}

Although we were initially puzzled when some individuals repeated workshops they had already attended, we came to realize that the cyclical nature of workshops allows participants to refresh their knowledge of aspects of research and accommodates the different impact of the same workshop at different points in particular projects or in an individuals' research career. In practice, people's knowledge and skills take time to develop, evolve and consolidate and they often have to take time out from their research endeavours. The most popular workshops in terms of repeat attendance have been those on focus groups, with those on analysis, using theory and writing up also attracting several repeat attendees.

\section{Achievements and future challenges}

Workshops have provided an insight for participants into the complexities and subtleties of the iterative approach. Aspects of this process are often only grasped after the workshops - or, hopefully,

Primary Health Care Research \& Development 2007; 8: 198-206 
through hands-on engagement with qualitative research rather than being described in abstract terms. The extended and intensive format of the workshops, whilst not being an easy option, allows for people to be introduced to, and process, complex research issues and concepts.

Through observing the research process as a whole over three days, my confidence improved greatly. The difficult obstacles faced in the early stages seem more worthwhile now I can better appreciate the possibilities that will become open to me later on.

(Master Class attendee, 2006)

A number of workshop participants' qualitative research careers, including gaining higher degrees, have burgeoned alongside the workshop programme (see Table 2). Others applied their new knowledge and have given small training workshops themselves (Research Fellow, attendee February, 2002). Another, at the planning stages of preparing a questionnaire incorporating open questions, rewrote this questionnaire following attendance at a workshop.

Teams undertaking qualitative projects have sent members (including non-medical staff who are transcribing complex focus groups) to gain skills and understanding. As organizers, we have learnt that offering long-term support and advice to researchers and their teams (both pre and post

Table 2 Designation, number of workshops attended, higher degrees achieved and ongoing work being undertaken using qualitative methods

\begin{tabular}{llll}
\hline Designation & $\begin{array}{l}\text { No. of } \\
\text { workshops } \\
\text { attended }\end{array}$ & $\begin{array}{l}\text { Higher } \\
\text { degrees } \\
\text { achieved }\end{array}$ & $\begin{array}{l}\text { Ongoing } \\
\text { work } \\
\text { 2006-present }\end{array}$ \\
\hline $\begin{array}{l}\text { General } \\
\text { practitioner }\end{array}$ & 5 & PhD & \\
$\begin{array}{c}\text { General } \\
\text { practitioner }\end{array}$ & 5 & & PhD \\
$\begin{array}{l}\text { Health visitor } \\
\text { Health visitor }\end{array}$ & 3 & $\mathrm{MSc}$ & \\
$\begin{array}{l}\text { Health visitor } \\
\text { Research fellow }\end{array}$ & 1 & $\mathrm{MA}$ & \\
$\begin{array}{l}\text { Nurse } \\
\text { Nurse }\end{array}$ & 3 & $\mathrm{Mh}$ & \\
Nurse & 3 & $\mathrm{PhD}$ & \\
PAMS & 1 & $\mathrm{PhD}$ & \\
PAMS & 5 & $\mathrm{MA}$ & \\
\hline
\end{tabular}

Primary Health Care Research \& Development 2007; 8: 198-206 workshops) is valuable to participants and enables them to gain maximum benefit from them.

There is always a challenge in attempting to evaluate such training provision, where short-term benefits may appear slight and longer-term benefits are hard to measure. There are also many intangibles, such as the gradual development of an environment more conducive to research.

As participants have become more proficient, workshops have given them the confidence to undertake qualitative work, to win over skeptical colleagues and to justify the validity of their work and methods to research committees. Reassurance has been provided that we all struggle with similar issues and constraints in the real world of designing and running projects.

I enjoyed working with others today and getting to know what other people are doing in their own research.

(Master Class attendee, 2006)

Sharing ideas and an opportunity to network with fellow qualitative researchers can reassure and encourage researchers and this has been an important aspect for attendees. Some experienced workshop participants have more recently offered support for future workshops, indicating an increase in their confidence and progression in the field.

Although we continue to offer workshops on generating and analyzing interview and focus group data, recent Master Classes have provided more specifically focussed, discrete drop-in sessions, such as using theory and writing for journals. These are designed to reflect the differing levels of experience and stages in research projects. Individuals can attend the workshop most timely and relevant to their current needs, or one which allows them to refresh their skills and knowledge with regard to a specific research task. However, many people attend all sessions, suggesting that a lack of appropriate local research training continues to shape participation in our workshops.

A fantastic overview, found it very inspirational. Food for thought writing up my $\mathrm{PhD}$ research proposal. Thanks!

(Master Class attendee, 2006)

Consultation slots are incorporated into the Master Class programme. These allow people to obtain individual guidance with regard to specific 
research projects proposals or draft papers for publication. Material from researchers is given in advance to the facilitator, so that these can be used to full advantage. We plan to continue offering these consultation slots and are constantly looking at feedback to see what other approaches we might introduce. For example, running workshops for cohorts of researchers is also being considered and asking for expression of interest in types of workshops was considered useful by one participant. Question and answer sessions during and between workshops were also considered useful additions as were workshops for innovative ways of writing up and additional critical appraisal sessions on theoretical articles. Evening or weekend workshops for active researchers would negate the need to negotiate time off work, for others this is precious family time.

The workshop format has highlighted the limitations of working with another researcher's data, with the omission of contextual information and the challenges this presents for interpretation. Understandably, some participants have suggested bringing their own data to workshops for coding. Not having their own, current data to work on was considered as a disadvantage for some novice researchers. We initially considered this idea to be unworkable - not least because of assurances regarding confidentiality given to respondents. However, this could perhaps be a service provided by the facilitator as part of ongoing consultancy arrangements.

The workshop facilitator has given the network a commitment to offer advice and support to workshop attendees via Email and, where appropriate, telephone conference calls with researchers and the WoReN facilitator. People often research in relative isolation and this can be lonely and dispiriting. One participant stated that it is useful to be able to access both a series of workshops in order to help build up one's skills in qualitative research step by step as well as ongoing, individual network support with.

\section{Advice to other research trainers}

Recent workshops have been particularly rewarding for everyone as they have attracted researchers who were well advanced in their projects. This, in turn, afforded less-experienced participants valuable insights into the issues likely to arise at later stages in their own research.

In addition, we have identified (Eakin and Mykhalovskiy, 2005; Madill et al., 2005) a new audience in supervisors who are not versed in qualitative research methods, but who are now encountering students who wish to undertake qualitative research.

Some have attended workshops in order to familiarize themselves with this approach, to explore what training is available for their students and to obtain insights into the assumptions which underpin their students' research endeavours. These participants have also been interested in exploring possibilities for training students in their own departments, where such provision is lacking but is now in more demand. Perhaps this offers us scope in the future to provide consultancy/clinic sessions aimed at non-expert supervisors who work with more traditional research methods.

\section{Key learning}

We consider there is a need for a 'joined-up' approach rather than just providing one-off workshops. This ensures that there is room for development for individual researchers. It is also important to remain responsive to the changing requirements of participants, employers, funders, potential trainers and national NHS requirements.

\section{References}

Barbour, R.S. 2001: Checklists for improving rigour in qualitative research: a case of the tail wagging the $\operatorname{dog}$ ? British Medical Journal 322, 1115-17.

Barbour, R.S. 2003: The newfound credibility of qualitative research? Tales of technical essentialism and co-option. Qualitative Health Research 13, 1019-27.

Barbour, R.S. and Members of WoReN. 2000: Acquiring qualitative skills for primary care research. Review and reflections on a three-stage workshop. Part 2: analysing interview data. Family Practice 17, 83-89.

Barbour, R.S., Featherstone, V.A. and Members of WoReN. 2000: Acquiring qualitative skills for primary care research. Review and reflections on a three-stage workshop. Part 1: using interviews to generate data. Family Practice 17, 76-82.

Barry, C., Britten, N., Barber, N., Bradley, C. and Stevenson, F. 1999: Using reflexivity to optimize team-work in qualitative research. Qualitative Health Research 9, 26-44.

Primary Health Care Research \& Development 2007; 8: 198-206 
Eakin, J. and Mykhalovskiy, E. (2005) Teaching against the grain: the challenges of teaching qualitative research in the health sciences. Forum: Qualitative Social research, 6, Article 42. Online at http://www.qualitative-research.net/ fqs-texte/2-05/05-2-42-e.pdf

Madill, A., Gough, B., Lawton, R. and Stratton, R. 2005: How should we supervise qualitative projects? The Psychologist 18, 616-18.
Mant, D., Del Mar, C., Glasziou, P., Knottnerus, A., Wallace, P. and van Weel C. 2004: The state of primary-care research. The Lancet 364, 9438, 1004-1005.

Poland, B. and Pedersen, A. 1998: Reading between the lines: interpreting silences in qualitative research. Qualitative Inquiry 4, 293-312. 